\title{
Homelessness in Higher Education is not a Myth: What should Educators be doing?
}

\author{
Angela Karlin ${ }^{1} \&$ Barbara N. Martin ${ }^{2}$ \\ ${ }^{1}$ Assistant Vice Provost, University of Kansas, Lawrence, Kansas, USA \\ ${ }^{2}$ Professor, University of Central Missouri, Warrensburg, Missouri, USA \\ Correspondence: Barbara N. Martin, School of Professional Education and Leadership, University of Central \\ Missouri, Warrensburg, MO., USA. E-mail: bmartin@ucmo.edu
}

Received: March 22, $2020 \quad$ Accepted: April 16, $2020 \quad$ Online Published: April 21, 2020

doi:10.5539/hes.v10n2p164 URL: https://doi.org/10.5539/hes.v10n2p164

\begin{abstract}
This paper investigated homelessness and housing insecurity on college campuses in the United States. Using a mix design and framed by the theoretical frameworks of resiliency and social justice theories, this research sought to assess the barriers and interventions, if any, for students encountering homelessness while in college. The data analysis found three recurring themes: Education regarding homelessness, resource development, and the elimination of barriers. Research from this study underscored the need for interventions to be developed to assist the student in supporting retention. Additionally, the development of interventions allows faculty and staff to advocate for students while helping the university in meeting enrollment and graduation goals.
\end{abstract}

Keywords: higher education, homelessness, resiliency, social justice

\section{Introduction}

\subsection{Statement of the Problem}

A significant gap in the research exists as few studies on homeless college students have been conducted (Crutchfield et al. 2016). Colleges have a stake in the success of their students and need to create interventions, grounded in data to help students overcome barriers to success. Broton and Goldrick-Rab (2016) stated institutional practices and policies contribute to the issue and need to be addressed at the local level, thus eliminating those barriers and creating supports to enhance the chances of retention and success. Research is in its infancy stages "when it comes to explaining how students experience these challenges, when and where they obtain help, and how needs insecurity affects their schooling" (Broton \& Goldrick-Rab, 2016). The problem, simply stated, is that institutions have few, if any, resources in place to assist students experiencing housing insecurity. Higher education personnel know little about how best to support students that are homeless within the context of financial aid regulations and the constraints of institutional knowledge and budgets.

\subsection{Significance of the Problem}

Homeless students at the post-secondary level deserve a level playing field as they work to obtain a degree. Creating interventions to enhance persistence and completion while providing for basic needs is in both the institutions' and the students' best interests (Chapalot et al., 2015). Empowering students to utilize available resources and creating a comprehensive approach to issues that limit educational success, such as housing insecurity, builds trust with the community and combats the problem of access (Crutchfield et al., 2016).

Higher education institutions should be a safe zone for students to live and grow academically. Still, the lack of safe shelter or resources does not align with that ideal in practice at many schools. Advocacy groups have been successful in helping the homeless and unaccompanied youth in gaining access to support through the aid process. Still, that legislation stops short of meeting the homeless needs of these students (Crutchfield et al., 2016). Students have access to resources but not enough to solve the issues of housing and food security (Broton \& Goldrick-Rab, 2016). Higher education institutions need to address these issues in the context of providing services and linkages to the financial aid process for homeless students (Crutchfield et al., 2016).

\subsection{Relevant Research}

Significant barriers faced by homeless students can influence their ability to enroll and persist in higher 
education (Huang, Fernandez, Rhoden, \& Joseph, 2018). According to Huang et al. (2018, p.209), homeless youth are in "inherent disadvantage in an increasingly competitive and education nation." The instability of living arrangements causes stress and a focus on basic needs, thus creating roadblocks as students navigate postsecondary education (Chapalot et al., 2015; Crutchfield et al., 2016; Hallett, 2010; Huang et al., 2018). Many students struggle with the basic pieces of the college process, including applications, college visits, and application fees due to their lack of parental/adult support and financial stressors (Crutchfield et al., 2016; Huang et al., 2018). Hallett (2010, p.12) asserted housing instability "shapes access to college as well as how students participate in the educational process once they are admitted". Admitted students require monetary deposits to hold their spot in the class, housing deposits are required for on or off campus housing choices and travel to the college for orientations, course scheduling and financial aid assistance can prove difficult for those without proper guidance "to fully engage in the educational process" (Hallett, 2010, p.12).

Support in developing study skills, decision-making skills, and balancing academic workloads with working are obstacles that homeless students face due to the lack of stable homes and parental supports once in college (Crutchfield et al., 2016; Hallett, 2010, Huang, et al., 2018). Few colleges have programmatic interventions to help homeless students, partially due to the low numbers of homeless that enroll at any one institution (Hallett, 2010). Nevertheless, the need for supports is critical to lead to academic success and persistence toward a degree (Broton et al., 2014; Hallett, 2010). Students receiving supports described help from financial aid staff and others that build the connections to enhance the academic experience and eliminate non-academic stressors that assisted them in staying in school (Skobba et al., 2017). Obtaining a degree or other credential is critical in moving a homeless student beyond their current situation and out of the poverty cycle (Chapalot et al., 2015; Crutchfield et al., 2016; Hallett, 2010, Skobba, et al., 2017).

\subsection{Conceptual Framework}

Two theoretical frameworks guided understanding of this study and provided context to the issue. Resiliency theory (Masten \& Odbradovic, 2006) framed how impacted students were by homelessness and how the institution can support the resiliency of this population. Furthermore, the tenets of social justice and critical social theory framed why this population of students needs support to retain and persist in higher education.

An area of research review was regarding the inequalities in access to education that are a social justice concern that is lived daily by those who are homeless (Ausikaitis et al., 2015). Even though the challenges to educational access, especially stable housing, the student experience was investigated initially through retention theory and then through resiliency theory.

A review of resiliency theory and its wide-ranging foci formed a more robust conceptual framework for this research. Since resiliency theory is so broad, the researcher narrowed the focus to the concept of adaptation, meaning how individuals create their path despite setbacks (Masten \& Odbradovic, 2006). Research by Masten and Odbradovic (2006), Masten et al. (2014), and others specifically explored the homeless student and the development of resiliency. Specifically, post-secondary resilience investigation for the homeless is few. Therefore, carefully examined were resiliency concepts surrounding student development to provide a conceptual framework for best practices in promoting student success and resiliency (Masten \& Odbradovic, 2006; Masten et al., 2014).

A study by Watt, Norton, and Jones (2013) applied resiliency theory to foster youth and how they navigate the systems within higher education. In working with these students, social workers began to view the individual students as survivors, "who had developed unique skill sets and utilized a wide array of resources" (Watt et al., 2013). Recognition of those experiences and seeing them as assets support the resiliency of the student and support a positive approach to interventions instead of using a deficit model (Watt et al., 2013). Moving from a caseworker model, and using resiliency as a means of empowerment, disrupts negative stigmas that foster youth and others, such as the homeless experience in society (Saleebey, 2000; Thomas, 2000; Watt et al., 2013). Students who felt included, especially those having experienced hardships, tended to be retained at a higher level and overcome negative self-perceptions (Thomas, 2000; Watt et al., 2013). The interventions created to support resiliency can help advance students 'educational goals and provide access to a better future. Access to education provides a mechanism to "build and maintain and middle-class lifestyle," which can change the trajectory of an individual (Chapalot et al., 2015). Eliminating barriers, including housing insecurity, can help many students who are mostly in marginalized groups (Brown, 2006). Thus, the resiliency theory tenets became a conceptual framework for this inquiry as access and persistence can be enhanced by this support of resiliency that is grounded in a review of social justice theory.

Similarly, homeless students endure many challenges in accessing higher education, including access (Chapalot 
et al., 2015). Similarly, students who fall into the categories of low income, homelessness, or other marginalized groups experience issues of equal access (Brown, 2006). Difficulties in accessing education create a "predetermined mold designed for school failure and social inequity" (Brown, 2006, p. 701). To facilitate student success and the elimination of barriers that perpetuate social inequities, educators need to create spaces for students to get the help and resources that they need to retain and persist (Ausikaitis et al., 2015; Brown, 2006; Chapalot et al., 2015). Through addressing the issues of the homeless students and providing interventions, the system can change "to allow for meaningful inclusion of everyone, particularly those who are consistently disadvantaged or marginalized" (Ryan, 2006, p. 6).

Change within the current higher education system must occur by understanding and then reacting to those barriers that do not allow for the inclusion of disadvantaged groups. Ryan (2006) administered social justice in ways that highlighted the need for integration and creating a path for all to be involved in standard social practices, such as schools and the communities. Higher education is not exempt from the challenges of homelessness. Through the two conceptual frameworks of resiliency theory and social justice theory, the researchers examined the creation of best practices, with the ultimate goal of eliminating obstacles as homeless students work to obtain a degree.

\subsection{Research Design and Research Questions}

Critical paradigms provided the researchers "to promote the deconstruction and critique of institutions, laws, organizations, definitions, and practices for power inequities and inequities of effectiveness" (Guido, Chavez, \& Lincoln, 2010). Through careful analysis of the data, the critical theory lens allowed the researchers to engage in what Creswell (2014) referred to as "transformational advocacy". Creswell (2014, p. 189) defined mixed methods research as:

an approach to research in the world in the social, behavioral, and health sciences in which the investigator gathers both quantitative (closed-ended) and qualitative (open-ended) data, integrates the two and then draws a conclusion based on the combined strength of both sets of data to understand research problems.

The type of mixed design for this inquiry was what Creswell (2014) denoted as convergent design, whereby the quantitative data and the qualitative data are collected concurrently, and both datasets were analyzed separately, and then the results compared. Using the qualitative research approach enabled the researchers to develop descriptions and themes from the qualitative data while also providing quantitative analysis to triangulate the data (Creswell, 2014).

Furthermore, data gathered via interviews, document research, and focus groups allowed for the examination of concepts that enhances the development of a theory of fundamental social processes (Merriam \& Tisdell, 2016; Starks \&Trinidad, 2007). Thus, the focus of resiliency and social justice theory informed the inquiry as to the basis for assessing the effectiveness and development of interventions to eliminate barriers for homeless youth in higher education. The following research questions guided this investigation: What barriers exist in higher education for homeless students? And, How can institutions create policies and procedures to support the homeless student population in the context of resiliency and social justice?

\section{Method}

Purposeful sampling provided a mechanism for the researchers to answer the questions posed for the study by directly targeting participants that could give the best information to guide the study (Creswell, 2014). An initial selection of the participant group began with a review of the COSUAA membership. COSUAA is comprised of large, public institutions from across the United States. Using the membership of COSUAA $(n=130)$ as the survey population allowed for data collection across the country from similar institutions.

Additionally, a site selected from COSUAA membership was the setting of interviews and focus groups on enabling the researchers to collect qualitative data. Regional University (RU) was chosen because of proximity to the researchers and socioeconomically diverse undergraduate population. Interviews with crucial administrators $(\mathrm{n}=3)$, including Director of Student Financial Assistance, Director of TRiO Services, and Director of Housing, occurred on campus. The identification of these administrators was purposeful, as they are involved with students daily.

Furthermore, according to the triangulation of the data gathered from document analysis, survey data $(\mathrm{n}=130)$, and the interviews $(n=3)$, a focus group $(n=5)$ occurred. This group, consisting of a housing representative, financial aid counselling staff, and academic advisors, provided a varied perspective concerning students and their challenges in and outside of academics. The selection of the focus group permitted data collection from those who interact with students on a one to one basis and provides rich, thick descriptive data to the study. 
Using the voices of those working directly with students alongside the documents and survey data assisted the researchers in creating a narrative to answer the research questions and identify best practices to support resiliency (Creswell, 2014).

\subsection{Focus Group}

Conducting research using a focus group allowed the researchers an understanding of "how people feel or think about an issue, idea, product or service and are used to gather opinions" (Krueger \& Casey, 2015, p.6). Furthermore, using a focus group provided for the creation of a rich, thick narrative that added to data collected from the survey and interviews (Creswell, 2014; Merriam \& Tisdell, 2016). In addition to creating a narrative, the focus group provided a mechanism for the researcher to gain an understanding of the issues surrounding homeless youth. Furthermore, this group consisted of people who are closely involved with the creation or implementation of policies and procedures to help the homeless population. Krueger and Casey (2015) cited the use of focus groups as vehicles to help with decision-making and guiding program, policy, or service development and by using this means of data collection. Focus groups included financial aid administrators, student success personnel on campus, and student housing personnel $(n=5)$. The smaller size also created an environment for interactive discussion, which can give a different type of data not collected in an individual interview (Hennink, 2014). Within the group setting, everyday social interaction was observed, and data gathered while participants engage in discussion between each other (Hennink, 2014).

The focus group questions explored the treatment of homeless students in higher education, paying particular attention to the financial aid process. Open-ended questions allowed the researcher to collect meaningful data and provided descriptive data (Hennink, 2014; Krueger \& Casey, 2015; Merriam \& Tisdell, 2016). Employed was member checking to ensure that the researchers (Merriam \& Tisdell, 2016) captured the interpretation of words and ideas accurately. Using member checking allowed the researcher to capture content validity and strengthen the credibility of the research, which is crucial when using qualitative data collection (Creswell, 2014).

\subsection{Interviews}

In addition, the researchers conducted interviews $(n=3)$ to triangulate the findings further. Interview subjects included the Director of Student Financial Assistance, Director of Trio Services, and the Director of Student Housing at Regional University. The first interview was conducted face-to-face, while a second follow-up interview was conducted by telephone. Mertens (2005) claimed three benefits when conducting interviews: the depth of information, relationship development, and participant flexibility. These interviews included open-ended and semi-structured questions to establish an understanding of the construct of the homeless and to frame how participants shaped their experiences (Merriam \& Tisdell, 2016). To ensure accuracy, interviews were audiotaped to allow for engaged listening by the researcher during the interviews, as well as providing a mechanism for reflection and transcription of the data. Utilizing interviews assisted the researchers in strengthening data collection and "understanding the lived experience of other people and the meaning they make of that experience" (Seidman, 2013, p. 9).

\subsection{Online Questionnaire}

Administered was an online survey to the membership of COSUAA, allowing for the capture of national perspectives surrounding the issue of homeless students and retention with a return rate of $50 \%$ Results of the survey were analyzed using descriptive statistics and the portion that consisted of open-ended questions was coded and analyzed similarly as the focus groups and interviews. The descriptive statistics gleaned from the survey results were included in the analysis, which provided multiple sources for data (Yin, 2014). To evaluate the reliability of the survey (Creswell, 2014), the researcher utilized the test-retest reliability coefficient that determined the degree scores are consistent over time. The survey was administered to the same group of 19 educators within a three-week interval. Then the scores from the survey were correlated using the Pearson product-moment correlation coefficient $(r)$ to establish the stability for the reliability of the survey. A high coefficient of stability was the criterion for good test-retest reliability. For the survey, the correlation between the test and retest was .486 , which is significant at the .005 level according to the SPSS analysis, indicating the reliability of the survey.

\subsection{Document Analysis}

Examined were documents from the institution along with written and online resources to review and reflect on issues surrounding homeless youth and higher education. Public records created the ability for the researcher to understand things that "had taken place before the study began" (Merriam \& Tisdell, 2016, p. 164). The database 
of COSUAA members will further provide the researchers with an opportunity to review individual school websites for information on homeless student resources, if any. Analyzed were the following documents from the institution: financial aid policies and procedures as they relate to homeless students as defined by the FAFSA. Other documents included websites designed as resources for those in the housing crisis, as well as links to outside agencies that the school uses for referrals. As Merriam and Tisdell (2016, p. 246) noted, "Documents of all types can help the researcher uncover meaning, develop understanding, and discover insights relevant to the research problem".

\subsection{Setting}

The University setting where the qualitative research was conducted was purposefully selected from the member institutions of COSUAA. COSUAA is an advocacy and training organization for the financial aid profession and consists of large, public institutions with over 10,000 students. The institution was chosen based on its membership in COSUAA, the homeless student resources identified on its website, and the large percentage of Pell recipients that make up its student body, along with the close location proximity to the researcher. The concept of purposefully selected sites is based on what will "best help the researcher understand the problem and the research questions" (Creswell, 2014). Furthermore, purposeful sampling provided the researchers to select a site for richer and in-depth study to understand the problem better and answer the research questions (Creswell, 2014).

\subsubsection{Data Analysis}

Data obtained from the survey were tabulated and analyzed using SPSS Version 25. The Likert scale questions were measured with a scale that ranged from one to five, with five indicative of extensive. The mean and standard deviation for each item was determined to establish the frequency of responses. Using descriptive statistics provided summaries of some of the questions and data illustrated with charts and bar-graphs to provide a visualization of the frequency of responses, measures of central tendencies, and measures of variation (Fink, 2017). Questions that ask for counts and percentages of students to describe the schools' population were also tabulated to show the distribution and regional similarities if discovered.

Qualitative data analysis included the organization and cross-examining of data in ways that enable researchers to see patterns, identify themes, and make interpretations (Merriam \& Tisdell, 2016). According to Merriam and Tisdell (2016), this organization of the data was done as the researcher compares similar themes and examines how these relate to the variables within the sample population. The researchers used the traditional approach of coding as the themes emerged out of the data analysis (Creswell, 2014). The creation of essential categories, according to Merriam and Tisdell (2016), allowed for quick identification of the information as one works through the analysis of the data. Emerging themes were triangulated with other data collection tools to help guide the research.

\section{Results}

Below are the findings from the data analysis of the two research questions. Analyzed were the quantitative and qualitative data, along with documents from the institution.

\section{Q1. What barriers exist in higher education for homeless students?}

Qualitative data primarily answered research question two from participants in the three interviews, the focus group $(\mathrm{N}=5)$ and the survey $(\mathrm{N}=50)$. The survey provided a quantitative benchmark to assess the perception of homelessness on individual campuses. The survey question asked, "How much awareness is there on campus to the needs of students that are homeless?" The descriptive statistics displayed in Figure 1, illustrated most universities surveyed did not have much awareness of the issue of homelessness or did not view it as prevalent. The lower end of the scale encompassed $27 \%$ of the 50 respondents. 


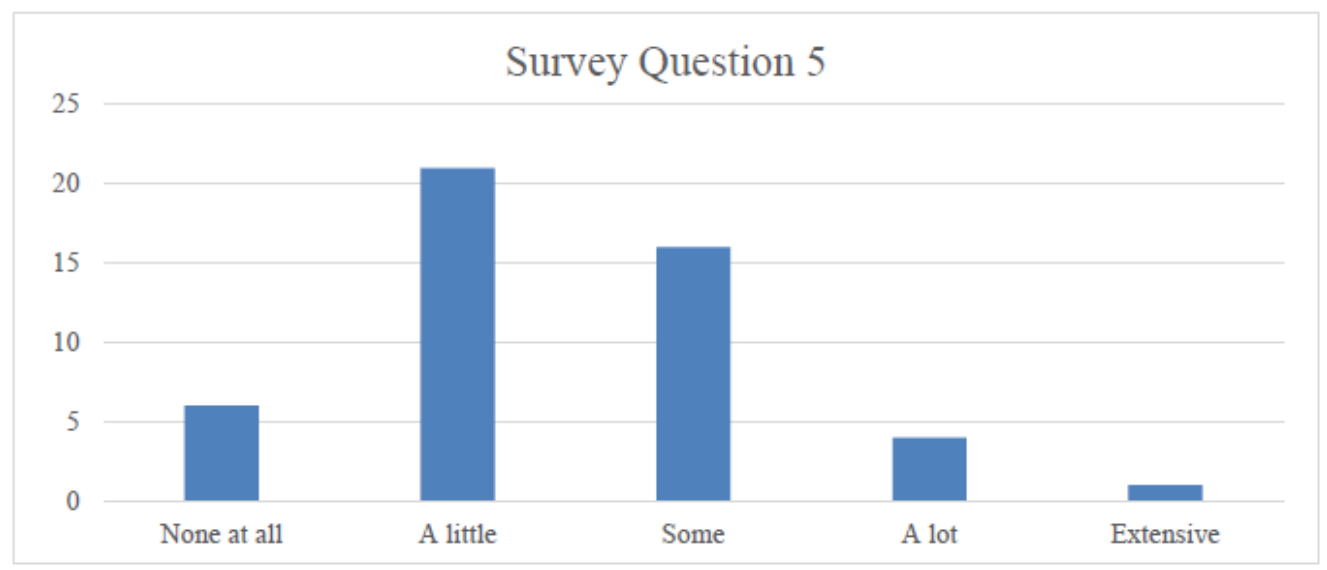

Figure 1. Survey Question 5 How much awareness is there on campus to the needs of students that are homeless? Note: $\mathrm{n}=50$ institutions

Specifically, the survey question asked if there is a general awareness on campus and revealed little to no awareness. Conversely, the participants of the interview and focus group cited specific issues to students' needs. Identified was financial resources as a barrier for students that are homeless as a thread during interviews and the focus group. Director 2 and 3 both stated finances are an issue, especially as they relate to housing. While "Cost is an issue," stated one focus group participant, "when we are on breaks, students that are homeless don't have a place to go, and if they decide to stay on campus over break, there is an additional fee." Director 3 explained that they could provide housing, but it comes with a cost, and "we don't provide differential pricing based on need." Students find themselves needing a place to stay, but the university cannot provide free placement and with many students stating, according to Director 3, "nobody wants to go into debt." From the university's standpoint, Director 3 stated, we work "diligently to be as equitable as possible because everything is an auxiliary, and everything is on the backs of other students." Providing discounts to one group based on a characteristic, such as need or housing security, impacts others. As a housing office, "we are unfortunately in a position to evaluate and make judgments about what is stress and a barrier versus exceptions to policy and that kind of stuff." Director 3 discussed the barriers and issues, but at the end of the interview stated, "It saddens my heart, but I can't...I don't know how to fix it".

Focus group participants had similar responses to the barrier question. The group discussed costs at length. Focus Group participant A stated, "How are they going to pay for it? Students may have necessities like a shower and a couch, but how do I get the next meal?" Another participant explained how barriers of documenting homelessness for financial aid and the FAFSA and cost affect students:

Mainly students are coming from low income, coming from first-generation backgrounds, especially students who are experiencing homelessness. This is the competing variable. If I don't continue with my education, if I don't have enough aid, if I can't prove that I'm independent, then I will be homeless, and I can't go back to that life. Therefore, it is a constant balance of whether or not they're able to maintain employment or get enough scholarships and also do well in their classes to make sure that they can persist.

Academic Success Coaches that comprised the Focus Group talked about the whole college student experience. Further noting how some students had to make decisions to work over attending class or pay for food rather than purchase a book or material for a class. Students also encounter relationship issues that have led to homelessness. One example is a woman who shared an apartment with a boyfriend. The coaches talked about how, when he left her, she was left with all the rent and could not afford the payment and "stopped attending class while she was trying to look for other options." Director 1 spoke of safety issues in relationships that caused students to leave stable housing or not have a safe place to go on breaks or summer vacation. "I have students who are in a transient situation; they are a temporary situation where shelter is not fixed." Some students, Director 1, shared, "have aged out of the foster care system and thus have no place to go." He went on to describe other families having a change in housing back at home, too.

The structures of higher education still think and act as if most students coming here are middle income or better from two-parent households, and Johnny's room is the same as when he left it with his trophies still there. He can come back at any time, and an apple pie is waiting for him. And the reality is more and more students do not 
have that situation. They're coming, especially the students we see [in TRiO\} are coming from rental properties which are by their nature short term.

Students in the situation described above, are not afforded a space in a house as their parents or support systems; simply do not have the room to shelter them any longer. Barriers exist as students experiencing homelessness "the traditional thing you might say is oh, someone looks like maybe they are dirty and haven't slept well." However, homelessness is not, as Director 1 stated, "How it is portrayed in the media or Hollywood." When asked about the prevalence of homelessness at RU, Director 1 stated, "more than people think, and I think the reason is that people have a lasting image in their mind to what homelessness looks like. The panhandler on Cleaver Boulevard, right?" It often happens when students "come to the University and whose parents then downsize or relocate to control expenses," and this means "the student does not have a home per se besides the one that they have temporarily while they're in classes." Awareness of the issue creates a barrier by having a conceptualization of homelessness that does not match what the student is experiencing.

Q2. How can institutions create policies and procedures to support the homeless student population in the context of resiliency and social justice?

In analyzing data to answer this question, the researcher asked participants in the focus group and interviews about their definition of resiliency. The overarching theme was about overcoming obstacles and continuing to one's goal. One respondent stated, "Someone flexible someone who bounces back is resilient." Director 3 explained resiliency as "being emotionally and cognitively and physically able to move on. You need to have the capacity to stick with". Focus group participants illustrated resiliency as the "overcoming of a challenge or hardship" and "having a goal that you stick to no matter what happens, whatever gets in your way keep pushing forward through adversity." After gathering the definitions, the researcher asked how higher education could support resiliency. A focus group participant explained that supporting resiliency was about helping students through the One Person campaign modelled off suicide prevention in Ireland.

They have a campaign that they use in Ireland. It is something that I brought with me to this job. It's the one-person campaign so as long as you have the one person and so everybody gets their person when they come into higher education. So, I try my best to be that one person for all my people. Therefore, it's not just about mental health, although that's a massive component of it. But making sure that they have somebody that they know cares, somebody, they know, and somebody they trust will be delicate with their situation. Be sensitive to their feelings and then also be honest and be consistent with them.

Creating a bond with students is difficult for academic success counselors, as they have large caseloads. One focus group participant discussed that "it can be tough with a large number of students, but letting know that you're the person that they can open up to and share things in that you are here to be a resource for them." It is difficult because students have complex situations, but the focus group was going to have a course in mental health first aid that "will be good to have tools to help students where they are."

Beyond tools to help students, questions asked of all participants about resources within the institution and community to assist students that were experiencing homelessness. RU has a food pantry called Campus Cupboard on campus and had some community partners, such as Catholic Charities and local shelters, that staff could refer students to in times of need. Survey participants mentioned emergency grant assistance United Way as a community partner, and 40 out of 50 respondents had a food pantry on campus.

No survey respondents gave feedback based on the question of "If you are not doing outreach, what kinds of programs or interventions would you like to see on your campus concerning helping the homeless students? When posed the same question, the RU participants cited that they would like to see "a one-stop-shop idea where we are all accessible to each other so that we can answer all the questions at their meeting." The focus group also talked of "serving as the middleman or advocate for the student; the mediator between the student and the campus because it's so unintuitive and intimidating." Acting as an advocate would allow " to have those conversations alongside the students with the other people who are experts in aid, academic realms or care team vicinity would be helpful."

\section{Discussion}

Organizing and examining the qualitative data to find emerging themes is a mechanism to achieve a deeper understanding of the data (Creswell, 2014). Emerging themes from the interview and focus groups and was enhanced by the review of the quantitative and qualitative analysis from the survey. Three themes presented in the data triangulation were Education surrounding the issue of student homelessness, Resource development, and Eliminating barriers through policy and procedure. 


\subsection{Education Regarding Homelessness}

As institutions work to recruit and retain students, there must be awareness that the students have experiences that exist beyond measurement by an academic transcript or vita. Creating a plan to assist practitioners in student development, financial aid, and retention offices to enhance access and student success by combating issues like homelessness counteracts issues of access and social justice (Chapalot et al., 2015; Crutchfield et al., 2016). Participants in the interview and focus group attest to the desire to influence a student's chance of success by eliminating the barriers but are impacted by a lack of education on homelessness and how that presents in higher education. Addressing issues by linking students to services to assist with housing and food insecurity is a key tenant of newer research, but these are not widely known across campus. As illustrated in the qualitative and quantitative analysis, participants were not sure about what policies and procedures existed to help students in crisis on their campuses. Moreover, in basic document analysis on RU's website, there were no resources for students to access issues with shelter or housing for emergent situations quickly.

Creating a safety net for students encountering housing instability addresses the need for interventions to support resiliency and the social justice concerns surrounding access to higher education. Including homeless students in the narrative of higher education attainment supports diversity and limits the marginalization of the underrepresented, including students of color and of different orientations that need additional supports to be successful (Hallett \& Crutchfeld, 2017). Students without that safety net and no guidance have more difficulty in engaging in the educational process (Hallett, 2010). Data collected in the focus group spoke to the need for that safety net and the ability for students to be able to focus on their academics without the additional stressors of finances and housing. Academic Success Coaches speaking about being an advocate for their students in crisis aligns with the research by Marshall (2004) that contended professionals within higher education do not have a grasp on what they can do to assist the marginalized and are not educated in how to address issues of social justice. Data from the survey, focus groups, and interviews illustrated the lack of conviction when speaking about what resources were available and demonstrated a lack of awareness about policy and procedures surrounding the issue of homelessness. Navigating the systems within the institution proved challenging for administrators and staff as they work to advocate for students and help them break out of the situation of poverty and disrupt the systems of "inequity that continue to marginalize homeless students in higher education (Gupton, 2017).

Besides the notion of creating supports to assist students, the concept of homelessness, and how it influences students was interpreted in many different ways across the data. Data collected via the interviews found that two of the three directors had less of a student-focused approach to how they viewed students in insecure housing situations. Besides, homelessness was often described in the qualitative analysis linked with the words mental illness. Students finding themselves in an insecure housing situation can be in a variety of situations, with mental illness not necessarily being one.

\subsection{Resource Development}

The data suggested that administrators often had limited awareness of resources on or off-campus that could help a student outside of the classroom. For example, data collected about policy and procedures to help students was limited from the survey participants and non-existent with the participants in the on-campus visit by the researcher. Not having a clear path to interventions or resources does not allow the student to get assistance without barriers. The data was evident in the focus group that the referral to the campus Care team was ambiguous and did not provide follow up for the staff that made the referral. This led to a lack of confidence in the campus's ability to triage and treat the issues. Connection to campus is essential to support a student academically and socially.

The conceptual frameworks cited the need for students to feel connected to the campus as a component of retention theory. This theme was echoed in the context of resiliency theory as education provides a means to escape homelessness through the creation of supports and relationships (Gupton, 2017). In addition, the promotion of mentors to promote a positive environment of support and encouragement is a way, according to Hallett (2012), to limit additional risk for a student and improve their achievement. Building the support network enhances trust and relationships with adults and peers within the institution. Homeless students due to their unstable environments do not have long-term relationships with mentors and other means of support, which are critical to developing skills to react to the atmosphere of higher education and coping with stressors (Gupton, 2017; Stratton et al., 2007).

Furthermore, institutional interventions that are currently in place are sporadic at RU and do not examine the structural changes to serve students, but tend to see interventions as a quick fix. Hallett and Crutchfeld (2017) 
advocated for more of a holistic and fundamental approach to invoke change instead of operating in a reactionary environment. Securing a fix for a housing issue is a start, but it is not the entire solution to creating retention and completion success.

This housing insecurity and related financial factors limit the ability of the student to be involved in social and academic activities regardless of why they become homeless. A focus group participant echoed this concept by illustrating the paradox of working versus going to class. They explained how the student struggled with the decision. Disconnecting from the goal of graduation or retention to the next semester causes not only academic stress, but also isolation from peers and the college experience (Kerby, 2015). An institution cannot control for all external stressors for any student. Still, a basic understanding of the issues and how supports are created and implemented for retention impact provides context and buy-in from staff and faculty.

Besides the student experience, the data suggested a need for resources for faculty and staff in this space. Homelessness and housing insecurity are not just a problem for the low-income or mentally ill as the data from the interviews and focus groups illustrated. Many students are coming to college from home, but due to other factors, they have become housing insecure. Students that are estranged from family due to personal choices or sexual orientation are encountering housing insecurity (Hallett \& Crutchfield, 2017). Educating staff and faculty about housing insecurity would eliminate perceptions of the issue as one for poverty-stricken or the mentally ill. Data gathered during this research supports lack of awareness of the homeless situation and is supported by the survey.

\subsection{Elimination of Barriers}

Throughout the resiliency framework, many researchers discussed the creation of supports for students to feel a connection to the campus, peers, or faculty, and staff. Barriers created by the institution to protect resources or the perceived integrity of the very systems designed to support students are the culprits in creating ill will and a lack of trust in the system (Ausikaitis et al., 2015). Two of the Directors interviewed spoke of the systems as a necessity to protect resources and prevent the working of the system. Within the context of social justice, interventions are needed but have to be framed within the context of support, not as punitive. Supportive interventions require a greater scope than the traditional financial aid model that is the only official support in place at RU.

The focus group participants were appreciative of the emergency funds that sometimes were available to a student in a housing crisis. Still, the only students being assisted are the ones that are comfortable sharing their stories. There is some data available via the FAFSA regarding homelessness or the risk of being homeless, but overwhelmingly the institutions' surveys did no outreach based on that data. Also, most institutions had little or no understanding of the retention policy at their institution or the resources outside the food pantry that were afforded within the community or institution. Social capital is lacking for most students that are in the housing crisis or have been homeless before college attendance. This lack of capital, according to Skobba, Meyers, and Tiller (2018), limits the ability of people to secure help or benefits via their connectedness to a person or network. The network and systems within an institution of higher education are complex for any student, with or without strong social capital or networks. Adding the layer of low support or an emergency to the mix can erode the ability for the student to stay in class and realize their potential, as their basic needs are not being met (Hallett \& Crutchfield, 2017; Maslow, 1943). Integrating a student into the college fabric is a component of retention theory, but one that is hard to achieve without eliminating outside the classroom stressors. These "multiple threats to learning" are issues that are barriers to integration and challenge retention efforts surrounding academic success (Masten et al., 2014). Academic success and integration are the theoretical underpinnings of the Tinto (1987) retention theory. Research from this study shows barriers and perceptions exist which undermine the ability for a homeless student to succeed, despite resiliency.

\subsection{Conclusions}

Despite not having any formalized policy or procedure, staff and directors are navigating the systems in place at RU to find means to assist individual students. The interventions are not scaled to help everyone and are not grounded in data that can be accessed from the FAFSA. Academic success coaches in the focus group voiced their desire to find resources but had concerns about their caseload and referral methodology. The concept of advocacy and mentorship was clear within the focus group and supports resiliency concepts of forming relationships to foster a sense of belonging. This belonging generates an environment that supports student learning and retention (Kerby, 2015). Integration via student supports in the academic and social fabric of the institution is central to retention, especially those that are early in the students' academic career (Kalsbeek, 2013). 
Formulating these supports is difficult, as shown by the data collection. Resources are not well defined, well-funded, or well known by staff at the institutions surveyed. High profile imitative such as the work of TRiO at RU and food pantries across those schools on the survey, were well known and easily referenced for a student in need. The lack of housing interventions or the knowledge of a housing issue was prevalent in the research. Most institutions did not think there was much of a problem around the concept of homelessness despite what the national statistics revealed. Furthermore, one concludes that this lack of awareness correlates with the lack of policy and procedure to intervene for the homeless.

Additionally, the perceptions of staff surrounding the attributes of a student that is homeless were evident in the data collection. These perceptions suggest that there is a misalignment between what is happening on campuses and perceived reality. Unfortunately, the stigma of homelessness does not encourage students to self-report or tell their stories unless the trust is gained (Ausikaitis et al., 2015). Providing support to students must be framed respectfully and privately and will need to be created, as the current, traditional supports do not address the homeless student experience (Chapalot et al., 2015). Data collection illustrates the need for supports and education throughout the institution to support students with housing challenges. Although only personnel from one institution were interviewed, the survey data provided further information to assess the campus climate and concerns that surround this population from fifty institutions. Using this information as a starting point to build interventions to support the homeless student will help financial aid professionals and campus partners to begin the conversation.

\section{Implications for Practice}

Based on the results of the study, institutions need to be intentional about creating policies and procedures for assisting students experiencing homelessness. Financial Aid Offices, in conjunction with student support services and advisors, need to evaluate how students navigate processes on campus and how referrals are made. Additionally, staff and faculty need professional development opportunities to understand the homeless student experience. Higher Education personnel need to create a comprehensive list of all resources available to students in times of housing crisis. Besides, the administration will need to enhance the ability of all staff to disseminate this information so that students do not have to go to multiple offices to tell their stories. Furthermore, each University needs to create a website for emergencies including housing issues for students to access anonymously if they do not wish to share their situation with staff or faculty

\section{References}

Ausikaitis, A. E., Wynne, M. E., Persaud, S., Pitt, R., Hosek, A., Reker, K., \& Flores, S. (2015). Staying in school: The efficacy of the McKinney-Vento Act for Homeless Youth. Youth \& Society, 47(5), 707-726. https://doi.org/10.1177/0044118X14564138

Broton, K., \& Goldrick-Rab, S. (2017). Going without: An exploration of food and housing insecurity among undergraduates. Educational Researcher, 47(2), 121-133. https://doi.org/10.3102/0013189X17741303

Broton, K., \& Goldrick-Rab, S. (2016). The dark side of college (un) affordability: Food and housing insecurity in higher education. Change: The Magazine of Higher Learning, 48(1), 16-25. https://doi.org/10.1080/00091383.2016.1121081

Brown, K. M. (2004). Leadership for social justice and equity: Weaving a transformative framework and pedagogy. Educational Administration Quarterly, 40(1), 77-108. https://doi.org/10.1177/0013161X03259147

Chaplot, P., Cooper, D., Johnstone, R., \& Karandjeff, K. (2015). Beyond financial aid: How colleges can strengthen the financial stability of low-income students and improve student outcomes. Retrieved from https://www.luminafoundation.org/beyond-financial-aid

Creswell, J. W. (2014). Research design: Qualitative, quantitative, and mixed methods approaches. Thousand Oaks, CA: Sage Publications.

Crutchfield, R. M., Chambers, R. M., \& Duffield, B. (2016). Jumping through the hoops to get financial aid for college students who are homeless: Policy analysis of the college cost reduction and access act of 2007. Families in Society, 97(3), 191-199. https://doi.org/ 10.1606/1044-3894.2016.97.25

Guido, F. M., Chavez, A. F., \& Lincoln, Y. S. (2010). Underlying paradigms in student affairs research and practice. Journal of Student Affairs Research and Practice, 47(1), 1-22. https://doi.org/10.2202/1949-6605.6017

Gupton, J. T. (2017). Campus of opportunity: A qualitative analysis of homeless students in community college. 
Community College Review, 45(3), 190-214. https://doi.org/10.177/009155211700465

Hallett, R. E. (2010). Homeless: How residential instability complicates students' lives. About Campus, 15(3), 11-16. https://doi.org/10.1002/abc.20023

Hallett, R. E., \& Crutchfield, R. (2017). Special issue: Homelessness and housing insecurity in higher education: A trauma-informed approach to research, policy and practice. ASHE Higher Education Report, 43(6), 1-129. Retrieved from https://onlinelibrary-wiley-com.proxy.mul.missouri.edu/doi/full/10.1002/aehe.20122

Hennink, M. M. (2013). Focus group discussions. New York, NY: Oxford University Press.

Huang, H., Fernandez, S., Rhoden, M. A., \& Joseph, R. (2018). Serving former foster youth and homeless students in college. Journal of Social Service Research, 44(2), 209-222. https://doi.org/10.1080/01488376.2018.1441096

Kalsbeek, D. H. (2013). Reframing retention strategy for institutional improvement. San Francisco, CA: Josey Bass.

Kerby, M. B. (2015). Toward a new predictive model of student retention in higher education: An application of classical sociological theory. Journal of College Student Retention, 17(2), 138-161. https://doi.org/10.1177/1521025115578229

Krueger, R. A., \& Casey, M. A. (2015). Focus groups: A practical guide for applied research. Thousand Oaks, CA; Sage Publications.

Marshall, C. (2004). Social justice challenges to educational administration: Introduction to a special issue. Educational Administration Quarterly, 40(1), 3-13. https://doi.org/10.1177/0013161X03258139

Maslow, A. H. (1943). A theory of human motivation. In J. M. Shafritz, J. S. Ott, \& Y. S. Jang (Eds.), Classics of Organization Theory (6th ed.) (167-178). Belmont, CA: Wadsworth.

Masten, A. S. (2007). Resilience in developing systems: Progress and promise as the fourth wave rises. Development and Psychopathology, 19(03), 921-930. https://doi.org/10.1017/S0954579407000442

Masten, A. S., Cutuli, J. J., Herbers, J. E., Hinz, E., Obradović, J., \& Wenzel, A. J. (2014). Academic risk and resilience in the context of homelessness. Child Development Perspectives, 8(4), 201-206. https://doi.org/10.1111/cdep.12088

Masten, A. S., \& Obradovic, J. (2006). Competence and resilience in development. Annals of the New Academy of Sciences, 1094, 13-27. https://doi.org/10.1196/annals.1376.003

Merriam, S. B., \& Tisdell, E. J. (2016). Qualitative research: A guide to design and implementation. San Francisco, CA: John Wiley \& Sons.

Mertens, D. M. (2005). Research and evaluation in education and psychology: Integrating diversity with quantitative, qualitative and mixed methods (2nd ed.). Thousand Oaks, CA: Sage.

Mertens, D. M. (2007). Transformative paradigm mixed methods and social justice. Journal of Mixed Methods Research, 1(3), 212-225. https://doi.org/10.1177/1558689807302811

Ryan, J. (2006). Inclusive leadership and social justice for schools. Leadership and Policy in Schools, 5(1), 3-17. https://doi.org/10.1080/15700760500483995

Saleebey, D. (2000). Power in the people: Strengths and hope. Advances in Social Work, 1(2), 127-136. https://doi.org/10.18060/18

Seidman I. (2013). Interviewing as qualitative research: A guide for researchers in education and the social sciences. New York, NY: Teachers College Press.

Skobba, K., Meyers, D., \& Tiller, L. (2018). Getting by and getting ahead: Social capital and transition to college among homeless and foster youth. Children and Youth Services Review, 94(2018), 198-206. https://doi.org/10.1016/j.childyouth.2018.10.003

Starks, H., \& Trinidad, S. B. (2007). Choose your method: A comparison of phenomenology, discourse analysis, and grounded theory. Qualitative health research, 17(10), 1372-1380. https://doi.org/10.1177/1049732307307031

Stratton, L. S., O’Toole, D. M., \& Wetzel, J. M. (2007). Are the factors affecting dropout behavior related to initial enrollment intensity for college undergraduates? Research in Higher Education, 48(4), 453-485. https://doi.org/ 10.1007/s1162-006-9033-4 
Thomas, S. L. (2000). Ties that bind: A social network approach to understanding student integration and persistence. The Journal of Higher Education, 71(5), 591-615. https://doi.org/10.1080/00221546.2000.11778854

Tierney, W. G. (2015). Bringing it home: Understanding the lives of homeless youth. International Journal of Qualitative Studies in Education, 28(6), 757-758. https://doi.org/10.1080/09518398.2015.1017861

Tinto, V. (1987). Leaving college: Rethinking the causes and cures of student attrition. Chicago: University of Chicago Press.

Watt, T. T., Norton, C. L., \& Jones, C. (2013). Designing a campus support program for foster care alumni: Preliminary evidence for a strengths framework. Children and Youth Services Review, 35, 1408-1417. https://doi.org/10.1016/j.childyouth.2013.06.002

Yin, R. K. (2014). Case study research: Design and methods. Thousand Oaks, CA: Sage.

\section{Copyrights}

Copyright for this article is retained by the author(s), with first publication rights granted to the journal.

This is an open-access article distributed under the terms and conditions of the Creative Commons Attribution license (http://creativecommons.org/licenses/by/4.0/). 